\title{
Ecological Sensitivity Evaluation of Tourist Region Based on Remote Sensing Image - Taking Chaohu Lake Area as a Case Study
}

\author{
Y Lin ${ }^{1.2 . *}, \mathrm{~W} . J . \mathrm{Li}^{1.2}, \mathrm{~J} \mathrm{Yu}{ }^{1.2}, \mathrm{C} . \mathrm{Z} . \mathrm{Wu}^{3}$ \\ 1、College of Surveying and Geo-Informatics, Tongji University, Shanghai 200092; \\ 2、Research Center of Remote Sensing and Spatial Information Technology, Tongji University, Shanghai 200092; \\ 3、 College of Architecture and Urban Planning, Tongji University, Shanghai 200092 ( linyi, 1633289, 1130485)@ tongji.edu.cn
}

\section{Commission III ICWG III/IVc}

\begin{abstract}
KEY WORDS: image automatic classification, analytic hierarchy process, equal interval reclassification, ecological sensitivity analysis
\end{abstract}

\begin{abstract}
:
Remote sensing technology is of significant advantages for monitoring and analysing ecological environment. By using of automatic extraction algorithm, various environmental resources information of tourist region can be obtained from remote sensing imagery. Combining with GIS spatial analysis and landscape pattern analysis, relevant environmental information can be quantitatively analysed and interpreted. In this study, taking the Chaohu Lake Basin as an example, Landsat-8 multi-spectral satellite image of October 2015 was applied. Integrated the automatic ELM (Extreme Learning Machine) classification results with the data of digital elevation model and slope information, human disturbance degree, land use degree, primary productivity, landscape evenness, vegetation coverage, DEM, slope and normalized water body index were used as the evaluation factors to construct the eco-sensitivity evaluation index based on AHP and overlay analysis. According to the value of eco-sensitivity evaluation index, by using of GIS technique of equal interval reclassification, the Chaohu Lake area was divided into four grades: very sensitive area, sensitive area, sub-sensitive areas and insensitive areas. The results of the eco-sensitivity analysis shows: the area of the very sensitive area was $4577.4378 \mathrm{~km}^{2}$, accounting for about $37.12 \%$, the sensitive area was $5130.0522 \mathrm{~km}^{2}$, accounting for about $37.12 \%$; the area of sub-sensitive area was $3729.9312 \mathrm{~km}^{2}$, accounting for $26.99 \%$; the area of insensitive area was $382.4399 \mathrm{~km}^{2}$, accounting for about $2.77 \%$. At the same time, it has been found that there were spatial differences in ecological sensitivity of the Chaohu Lake basin. The most sensitive areas were mainly located in the areas with high elevation and large terrain gradient. Insensitive areas were mainly distributed in slope of the slow platform area; the sensitive areas and the sub-sensitive areas were mainly agricultural land and woodland. Through the eco-sensitivity analysis of the study area, the automatic recognition and analysis techniques for remote sensing imagery are integrated into the ecological analysis and ecological regional planning, which can provide a reliable scientific basis for rational planning and regional sustainable development of the Chaohu Lake tourist area.
\end{abstract}

\section{INTRODUCTION}

As a new goal of tourism construction and management, ecological sustainable development has not only become an important direction, but also been the trend of ecological environment research and resource development (Chen, 2007a). Facing the impact and challenge of rapid economic development on the ecological environment, how to transform the industrial structure and make more effective utilization of tourism leisure resources in ecological environment, coordinating the relationship between scenic spots development and environmental protection by planning and design, is becoming a key of achieving the coordinated development between society and environment. The recent researches of ecological sensitivity mainly focus on some ecological issues, such as dynamic sensitivity analysis of soil erosion and land degradation, ecological sensitivity of the continental shelf, and ecological sensitivity of rainforest to selective logging in Australia (Yin et al. 2006a). Because of the large area and complex ecological environment, it is rare to take the basin as a research object for the ecological sensitivity analysis (She et al. 2012a.). Remote sensing technology has the characteristics of wide range, point-surface combination, multi-phase and repeated observation. It is suitable for obtaining and processing the environmental change information by using the quantitative analysis based on spatial distribution and landscape pattern (He, et al. 2001a). Based on these, this paper takes the Chaohu Lake Basin as the research area and analyses its land use/cover change by extreme learning machine (ELM) with multi-spectral satellite remote sensing images. Then on the basis of classification results, this paper analyses the ecological sensitivity of the Chaohu Lake area and assesses the service functions of the ecosystems in different regions, realizing the remote sensing quantitative analysis of the ecosystem in the Chaohu Lake basin. This study provides an effective technical support for the tourism leisure area coordinating development, regional wisdom planning and management around the Chaohu Lake area (ThanapakpawinP, et.al. 2007a).

\section{THE RESAERCH AREA AND DATA}

\subsection{Research area}

The Chaohu Lake Basin, whose total area is about $13500 \mathrm{~km}^{2}$, is located between the Yangtze River and the Huaihe River, which is surrounded by Yuping Mountain, Yefu Mountain, Dabie Mountain, Fanghu Mountain and Floating Mountain. The terrain is higher in west and lower in east with middle low-lying 
flat. And it belongs to the subtropical and warm temperate subtropical monsoon climate, with large annual variation of precipitation, uneven seasonal distribution and more concentrated in the summer (Miller L D, et, al. 1978). The Chaohu Lake National Tourism and leisure area, which is the first national tourism and leisure area created by the local government, is located in Hefei, Anhui Province. Leisure area mainly includes Hefei Binhu New Area, Chaohu City, Huanglu Town, Qionglai Town, Huailin Town, Baishan Town, Tongda Town, Tangchi Town, Ketan Town, Yefushan Town, Luobu Town and Guohe Town, Feixi Sanhe Town, Yan Dian country and so on, concentrated contiguous, planning area with about $4000 \mathrm{~km}^{2}$. Among them, the core area of leisure area includes one lake, two cities and twelve towns, whose total area is about $2,000 \mathrm{~km}^{2}$. The Administrative Plan map of Chaohu Lake Basin is shown in Figure 1.

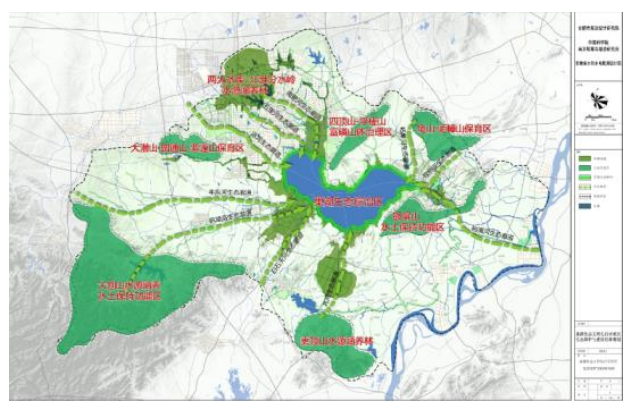

Figure 1 Administration planning map of Chaohu Lake

\subsection{Data introduction}

The data utilized in this paper consist of one Landsat- 8 satellite images and one vector file of the Chaohu Lake Basin both acquired in October 2015. The data covers an area of about
$13500 \mathrm{~km}^{2}$. In the process of ecological sensitivity analysis, digital elevation model (DEM) data and slope data, NDVI, NDWI, vegetation coverage, human disturbance, land use and landscape uniformity calculated based on the classification result map, are used. The Chaohu Lake basin satellite image is shown in Figure 2.

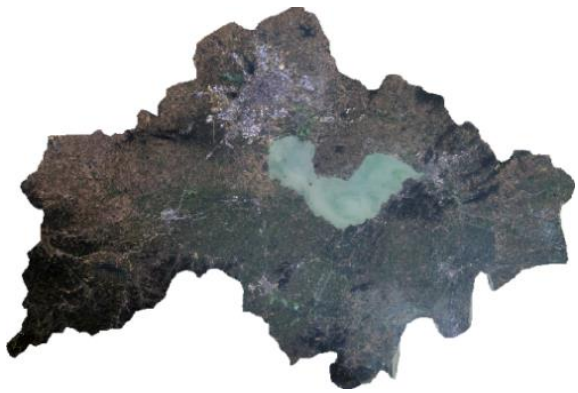

Figure 2015 Satellite imagery of Chaohu Lake Basin

\section{RESEARCH METHODS}

\subsection{Research Technology Roadmap}

The Chaohu Lake basin was taken as a case study in this paper, and the improved ELM classification method was used to classify the remote sensing image automatically. The ecological factors were calculated in every $5 \times 5$ window on the image. Based on the experts' scoring on the importance of ecological factors, AHP was used to get the weight, then superposition analysis was accomplished. Finally, the ecological sensitivity evaluation map was obtained by the equal intervals reclassification. The total technology road map of study is shown in figure 3
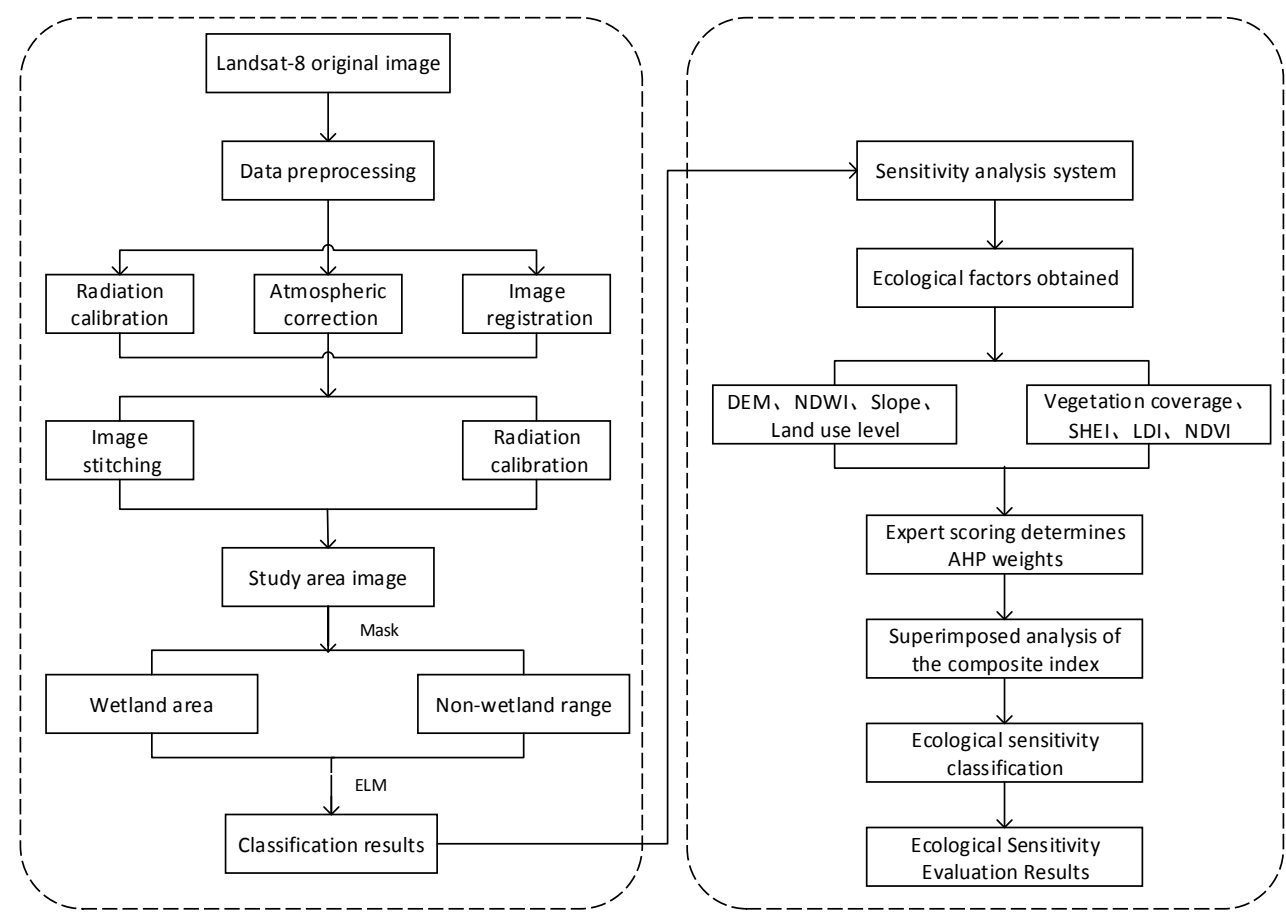

Figure 3 Technology road map 


\subsection{Data preprocessing}

Histogram matching and image registration of Landsat- 8 satellite imagery were carried out. After splicing the two adjacent images, the vector files of the research area were used for cropping, in order to obtain the remote sensing image of the study area. The ELM algorithm proposed by Huang (Lin, et,al. 2017a) is an easy-to-use and effective single hidden layer feedforward neural network with the advantages of fast learning speed and good generalization ability. However, the ELM is prone to overfitting and owns poor tolerance during the calculation process. Therefore a regularization diagonal matrix needs to be added to build a more stable and generalized ELM classification model. Based on this, this paper improved the ELM classifier by constructing the optimal regularization parameter diagonal matrix through the fish-swarm optimization algorithm (Lin, et,al. 2017a). According to the characteristics of the study area and "the national classification of land use status", as well as the principle, science, applicability and the principle of separability of remote sensing technology, the image of the study area was automatically classified into 7 categories, containing bare land, wetland, water, building, arable land, forest land and algae.

\subsection{The determination of evaluation unit}

The evaluation unit owns the attribute of consistency and is the basic evaluation area, which can objectively reflect attributes of entire study area. The determination of the unit should consider the characteristics of study area, the study methods and purpose. Due to the abundance of landscape resources and the complex types of land use in the study area, a window of 5 pixel $\times 5$ pixel was applied for ecological factors calculation. And pixels with a resolution of $30 \mathrm{~m} \times 30 \mathrm{~m}$ were selected as the evaluation units for the comprehensive eco-sensitivity analysis.

\subsection{Calculation of ecological factors}

\subsubsection{Terrain and Geomorphy}

\section{1) Digital elevation model (DEM)}

Elevation is an important factor in ecological environment. Normally, the air temperature decreases with the elevation increasing, and the whole ecosystem shows obvious vertical distribution. Therefore, elevation can be used as a factor to measure ecological sensitivity. The higher the elevation is, the more ecological fragile and eco-sensitive are. At the same time, the elevation has also become one of the restrictive factors in the scenic construction and landscape planning in varying degrees. In this paper, the elevation data obtained from relevant departments were normalized as the elevation value of each position.

\section{2) Slope}

For slopes, the effect of plant growth is mainly considered. Usually when the slope is greater than $25^{\circ}$, only the shrubs and small trees can grow, and when the slope is greater than $45^{\circ}$, even the turf is difficult to grow. According to the degree of topography, there are four slope types: flat slope $\left(<8^{\circ}\right)$, slow slope $\left(8^{\circ}-25^{\circ}\right)$, mid-slope $\left(25^{\circ}-45^{\circ}\right)$ and steep slope $\left(>45^{\circ}\right)$. In this paper, the slope data obtained from the relevant departments is normalized as the slope value of each position.

\subsubsection{Natural conditions}

\section{1) Normalized Difference Water Index (NDWI)}

The NDWI is the normalized ratio index of the green and nearinfrared bands. Generally, NDWI could extracts the water information well, so NDWI can be used as ecological factor of water ecological sensitivity analysis. Its expression can be shown in the formula (1):

$$
N D W I=\frac{P(\text { Green })-P(\text { NIR })}{P(\text { Green })+P(\text { NIR })}
$$

where, $P($ Green $)$ represents the green band, $P(N I R)$ represents the near infrared band. In this study, the normalized NDWI of each pixel is obtained by the green band and near-infrared band operations of the image.

\subsubsection{Vegetation Information}

\section{1) Primary productivity}

Primary productivity means the photosynthesis of green plants, which is the process that transform sunlight, inorganic matter, water and carbon dioxide to heat, oxygen and organic matter, which fixing inorganic carbon $(\mathrm{CO} 2)$ and transform to organic carbon (such as grape bran, starch, etc ). The Primary productivity is estimated by the Normalized Difference Vegetation Index (NDVI) in this paper. NDVI calculation is as formula (2):

$$
N D V I=\frac{P(N I R)-P(R)}{P(N I R)+P(R)}
$$

where $P(N I R)$ represents the near infrared band, $P(R)$ represents the infrared band.

\section{2) Vegetation coverage}

Vegetation coverage is estimated by the NDVI calculated from the corrected remote sensing image. Positive NDVI represents vegetation coverage, and it would increases with vegetation coverage increasing. In this paper, the model of vegetation coverage is built by using pixel bipartite model, as the formula (3) shows:

$$
F=\frac{N D V I-N D V I_{\min }}{N D V I_{\max }-N D V I_{\min }}
$$

where, $F$ denotes the vegetation coverage, $N D V I_{\max }$ and $N D V I_{\min }$ denote the maximum and minimum NDVI.

\subsubsection{Landscape Resources}

\section{1) SHEI (Shannon's Evenness index)}

The SHEI refers to that the Shannon diversity index divides the maximum possible diversity under a given landscape abundance which is the uniform distribution of each patch type. SHEI can reflect the degree that the landscape is dominated by one or a few superior plaque types and it is a powerful way to compare the diversity of different landscapes in different periods. The range of landscape evenness index is $[0,1]$. When it approaches 1 , the dominance is low, indicating that there is no obvious dominant type in the landscape and the class patches are evenly 
distributed in the landscape. The calculation formula (4) is as follows:

$$
\text { SHEI }=\frac{-\sum_{k=1}^{m} P_{k} \bullet \ln \left(P_{k}\right)}{\ln (m)}
$$

where, $P_{k}$ represents the area occupied by each patch type, and $m$ represents the total numbers of landscape patch types.
The human interference level refers to the impact of human behaviour or events on the ecosystem, community and population structure, including changing the effective utilization of resources, nutrients or changing the physical environment (White P S, 1985). In this paper, weights should be determined before calculating LDI (Landscape Development Intensity Index), and the weighting result determined by the reference "Landscape Development Intensity Index" (Brown M T, Vivas M B, 2005a) and "US Wetland Health Assessment Method" (Chen, et, al.2009) and some conditions on the ground, is shown in Table 1:

\subsubsection{Human activities}

\section{1) Human interference level}

\begin{tabular}{|c|c|c|c|c|c|c|c|}
\hline Types & Unused land & Water land & Water land & Water land & Forest land & $\begin{array}{c}\text { Agricultural } \\
\text { land }\end{array}$ & $\begin{array}{c}\text { Urban } \\
\text { settlement land }\end{array}$ \\
\hline $\begin{array}{c}\text { Land use } \\
\text { classification }\end{array}$ & Bare ground & Wetlands & Waters & Algae & Woodland & Arable land & Building \\
\hline $\begin{array}{c}\text { Classification } \\
\text { index }\end{array}$ & 0.5464 & 1 & 1 & 1 & 0.5556 & 0.1733 & 0.1152 \\
\hline
\end{tabular}

Table1 Chaohu Lake various land types of LDI weights

\section{2) Land use degree}

The degree of land use reflects the intensity of land developed by human beings. The basic idea is to divide the various types of land cover in the study area into four levels according to the degree of utilization, shown in Table 2. Then the proportion of each level is used to calculate the degree of land use, the calculation formula is shown in formula (5):

$$
L_{a}=100 \times \sum_{i=1}^{n} L_{i} \times A_{i}
$$

where, $L_{a}$ represents the degree of land use in the area, $L_{i}$ is the utilization intensity index of each type of land within the area, and $A_{i}$ is the proportion of this type in the area. Table 2 is land use classification index.

\begin{tabular}{|c|c|c|c|c|}
\hline Types & Unused land & Forest, grass, water & Agricultural land & $\begin{array}{c}\text { Urban settlement } \\
\text { land }\end{array}$ \\
\hline $\begin{array}{c}\text { Land use } \\
\text { classification }\end{array}$ & $\begin{array}{c}\text { Unused land, } \\
\text { beach }\end{array}$ & Forests, waters & Farmland, farms & Building \\
\hline Classification index & 1 & 2 & 3 & 4 \\
\hline
\end{tabular}

Table 2 Land use type intensity grading index

According to the graded index of intensity of land use type, the grading index is re-determined for the ecological sensitivity analysis. The greater intensity of land use type is, the more serious interference of the man-made factors are. The general development couldn't cause ecological changes, and the sensitivity is relatively small. Therefore, the greater land use intensity of the land type in the sensitivity analysis will obtain the less the weight, which determines the type of land-use rights and then normalized, the results are shown in Table 3:

\begin{tabular}{|c|c|c|c|c|}
\hline Types & Unused land & Forest, grass, water land & Agricultural land & $\begin{array}{c}\text { Urban settlement } \\
\text { land }\end{array}$ \\
\hline $\begin{array}{c}\text { Land use } \\
\text { classification }\end{array}$ & $\begin{array}{c}\text { Unused land, } \\
\text { beach }\end{array}$ & Forests, waters & Farmland, farms & building \\
\hline Classification index & 0.2 & 0.15 & 0.10 & 0.05 \\
\hline
\end{tabular}

Table 3 Chaohu Lake Basin land use types of weight

\subsubsection{Ecological factor calculation}

In the process of ecological factor calculation, the original data of DEM and slope are normalized for each position. NDVI,
NDWI and the vegetation coverage, the corresponding position values are obtained through the formula. Each position value of SHEI, human disturbance degree and land use degree were 
calculated according to the formula in the 5 pixcel $\times 5$ pixcel windows, and then traverse the entire image.

\section{5 determine the weight of ecological factors}

The Analytic Hierarchy Process (AHP) is used to determine the weight in this research. AHP is a multi-objective decision analysis method proposed by A.L. Saaty in the 1970s in the United States (Ma L.P, 2000a). This method mainly emphasizes the objectivity of human judgment in decision-making and is suitable to solve problems of multiple objectives and multiattribute. In the study, the expert scoring method was used to determine the role of ecological factors in the tourism development and construction of the Chaohu Lake tourist area. After the more important values were assigned to 1, 3, 5, 7, and 9 , and vice versa, $1,1 / 3,1 / 5,1 / 7,1 / 9$. The weights obtained by the AHP were tested for consistency, finally obtaining $C R=$ $0.099, C R<0.1$, so that the consistency of the judgment matrix can be acceptable, and finally got the weight shown in Table 4 .

\begin{tabular}{cccc}
\hline Target layer & Guidelines layer & Ecological factor & Weights \\
\hline Sensitivity & $\begin{array}{c}\text { Natural } \\
\text { Conditions }\end{array}$ & SLOPE & 0.1019 \\
evaluation & $\begin{array}{c}\text { Vegetation } \\
\text { information }\end{array}$ & NDWI & 0.078 \\
$\begin{array}{c}\text { Landscape } \\
\text { resources }\end{array}$ & $\begin{array}{c}\text { Negetation } \\
\text { coverage } \\
\text { SHEI }\end{array}$ & 0.1038 \\
human \\
activity & LDI & 0.1213 \\
& Land use level & 0.1880 \\
& & 0.1659 \\
\hline
\end{tabular}

Table 4 the weight of ecological factor

\subsection{Evaluation System Construction}

Using the normalized values of each factors, the comprehensive index for the entire research area was calculated by the weighted summation, then the comprehensive index for evaluating the sensitive state of Chaohu Lake area was constructed. Its expression is as shown in formula (6):

$$
E=\sum_{i=1}^{n} w_{i} \times p_{i}
$$

where, $E$ represents the desired comprehensive index of Chaohu Lake state evaluation, $w_{i}$ represents the weight of the ith evaluation index, $P_{i}$ represents the $i t h$ evaluation index, and $n$ represents the number of the evaluation index. The composite index reflects the different state levels of land use and vegetation coverage in the study area, and determines the corresponding ecological sensitivity level according to the grading numerical range of the total index.

\section{RESULTS AND ANALYSIS}

\subsection{Chaohu Lake image classification results}

The improved ELM method was used to classify the study area. The research area of the Chaohu Lake can be divided into seven types of landscapes: bare land, wetland, water, building, arable land, woodland and algae. The specific result is shown in Figure 4.

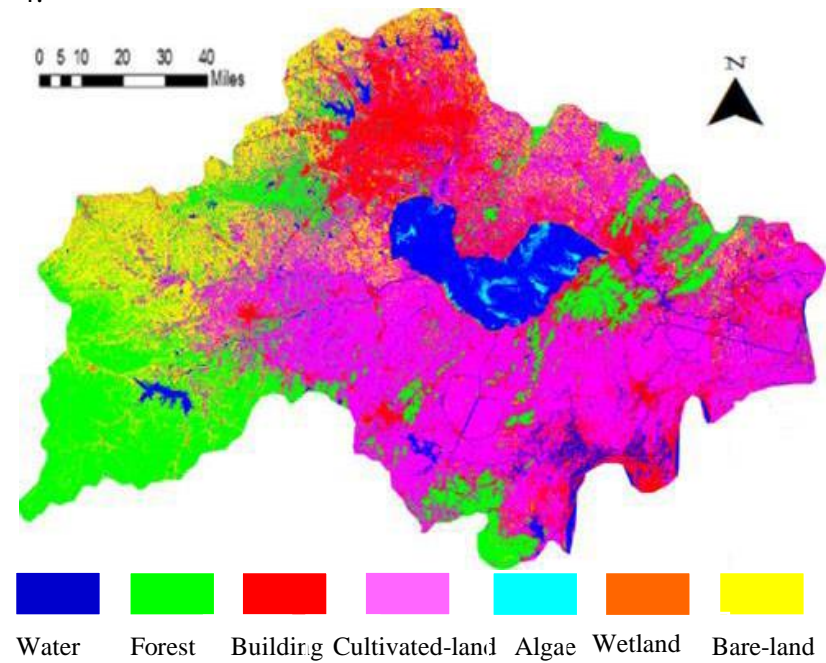

Figure 4 Chaohu Lake basin classification results

\subsection{Ecological Sensitivity Evaluation Results and Analysis}

Based on the obtained composite index, the ecological sensitivity for each pixel was evaluated, which ranges from 0 to 6.2672. According to the equal interval reclassification method in the GIS, the result could be divided into the very sensitive range of 4.7004-6.2672 Level, the sensitive level range of $3.1336-4.7004$, the sub-sensitive level range of 1.5668-3.1336, 
the insensitive level range of 0-1.5668. After traversing the entire image, an ecologically sensitive thematic map of four different levels of sensitivity is obtained (Zhang, et, al, 2015a).

\subsubsection{Ecological Sensitivity Evaluation Results}

The result of the sensitivity analysis is shown in Figure 5:

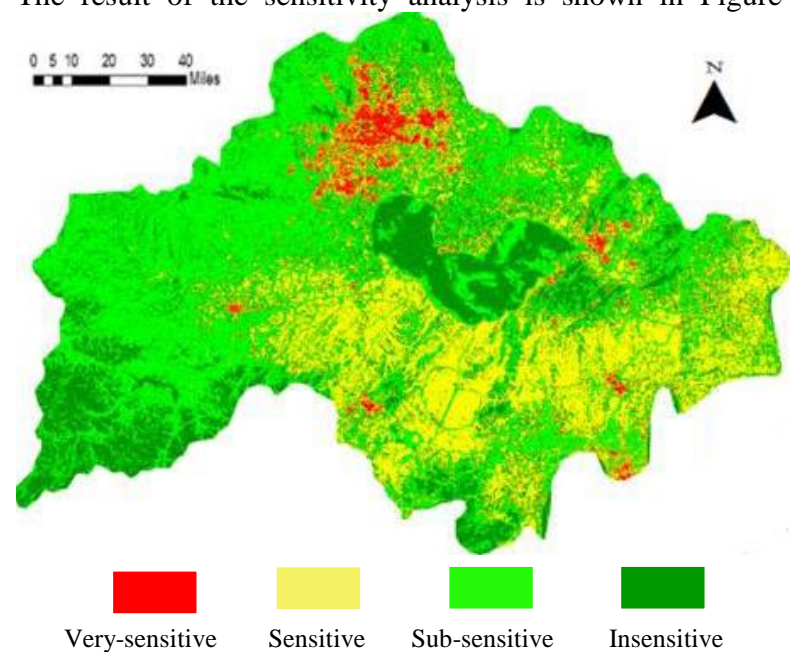

Among them, the insensitive area, sub-sensitive area, sensitive area and very sensitive area are represented by red, yellow, light green and dark green, respectively. The corresponding area of each level is shown in Table 5

Figure 5 Chaohu ecological sensitivity evaluation results

\begin{tabular}{|c|c|c|c|c|}
\hline Grading standards & $4.7004-6.2672$ & $3.1336-4.7004$ & $1.5668-3.1336$ & $0-1.5668$ \\
\hline Type & very sensitive & Sensitive & Sub-sensitive & Insensitive \\
\hline Color & Dark green & Light green & Yellow & Red \\
\hline Number of pixels & 5086042 & 5700058 & 4144368 & 424932 \\
\hline Area $\left(\mathrm{km}^{2}\right)$ & 4577.4378 & 5130.0522 & 3729.9312 & 382.4388 \\
\hline Proportion $(\%)$ & 33.12 & 37.12 & 26.99 & 2.77 \\
\hline
\end{tabular}

Table 5 Chaohu Lake basin sensitivity grading area and the proportion of all levels.

\subsubsection{Ecological Sensitivity Evaluation and Analysis}

According to the comprehensive sensitivity assessment, the proportion of the very sensitive area, the sensitive area, the subsensitive area and the insensitive area around the Chaohu Lake basin are $33.12 \%, 37.12 \%, 26.99 \%$ and $2.77 \%$ respectively. The ecological sensitivity of the Chaohu Lake basin is spatially different. The most sensitive areas are mainly located in the areas with high elevation and large terrain gradient. Natural disasters such as landslide and debris flow are prone to occur in this area. The insensitive areas are mainly distributed in the areas of gentle slope. The platform area is the focus area for towns and settlements; the sensitive areas and the sub-sensitive areas are mainly agricultural land and woodland (Dang G.F, Ji S.G. 2017a)

In general, people should pay more attention to the very sensitive areas and sensitive areas during the development and protection of the tourist attractions around the lake, such as Huanglu Town, Qionglai Town and the steeply-sloping areas in the woodland. The ecological environment in these areas is the most vulnerable. The ecological environment of the land is easily influenced by human activities and easily leads to different degrees of ecological and environmental problems. Especially in very sensitive areas, the ecological environment is hard to be restored if destroyed, and such areas should be regarded as ecological protection areas to safeguard the stability of the ecosystem by strengthening protection and ensuring the quality of the forests. Sensitive areas such as Binhu New District, Yandian Township, Sanhe Township, and part of cultivated land and forestland, which are crucial to the maintenance of very sensitive areas, are the protective barriers for the very sensitive areas. The ecological environment is relatively fragile and should be used as a controlled development area. The development of ecological industry could be promoted by increasing the forest coverage in the region, such as developing the planting industry with special features to promote environmental protection and economic development, increasing greening in urban areas and protection of lakes and shelterbelts (Dang and Ji. 2017a).

At the same time, the sub-sensitive areas are also crucial for the planning of tourist attractions. For example, the Yefushan Town and Tangchi Town are an isolated belt of sensitive areas. Since the area has a certain anti-interference ability, the development has little impact on the ecological environment, which can be used as a suitable development area. But it needs to pay attention to the environmental pollution caused by industrial waste. For the insensitive areas mainly for human production and life, such as Chaohu Lake and Hefei, are the basic conditions for the survival and development of residents in the basin. From this perspective, the economic development is 
more important than the ecological protection in the insensitive area. So it can be used as an economic development zone. Through the development of regional economy and the improvement of urban ecological conditions, the strategy of urban sustainable development should be strengthened so as to create a good living environment (LI, et. al. 2017a, Dang G.F, Ji S.G. 2017a)

\section{SUMMARY}

In this paper, the ecological sensitivity of the Chaohu Lake area was evaluated and analyzed through the automatic classification for remote sensing imagery and GIS spatial analysis technology. The study showed that:

1) Based on the analysis of the ecological sensitivity of a large area by remote sensing technology, quantitative information combined with spatial distribution were obtained, which could determinate the scope of the protection, restoration and development for ecological function zones. The results could contribute to form the multi-level transitional system, which consists of ecological protection zones, controlled development zones, development zones and economic development zones, as well. This has a macro-level guidance on strengthening the protection of biodiversity and promoting the sustainable development of Chaohu Lake tourist area.

2) Planning and construction of scenic tourist area is in a crucial period for the rapid development of urbanization in China. How to guide, control and guarantee the construction process with scientific theories and technologies, as well as how to scientifically implement regional planning and use the resources efficiently and intensively have become the severe problems that modern tourism development and construction urgently need to consider and solve. Using RS technology to extract various ground-object information and evaluate the ecological sensitivity for monitoring regional ecological environment could grasp various information such as resources utilization, spatio-temporal distribution and ecological environment changes in a large scale. It provides technical support and decision-making basis for the coordinated development of cities, towns and villages within the region.

3) On the basis of the ecological sensitivity results, some appropriate management and strategies on land use, water area management, forest planting and wetland maintenance in Chaohu Lake Basin could be proposed. For example, the land use structure could be optimized continuously and the water environment governance should be strengthened to construct of wetland as the core of the ecological network space system, and form a comprehensive and coordinated eco-optimization area of "building tillage wet", so as to better regulate the relationship between tourism construction development and ecological protection, and realize the sustainable development between human and nature in further tourism construction and resource development.

The eco-sensitivity analysis of tourism region is a comprehensive research covering different disciplines. Since the limitation of references and the complexity of reality, there are also some further works to be done: 1) How to optimize increase the classification algorithms to increase the accuracy and efficiency is a crucial aspect. Meanwhile how to select remote sensed imagery to make the balance between computation and accuracy needs to be considered as well. 2) There is still no complete and unified assessment system and model for eco-sensitivity, due to the complexity of reality.
Some limitation, therefore, exist during the selection of evaluation factors process.

\section{ACKNOWLEDGEMENTS (OPTIONAL)}

This project is funded by project of DAAD (No. 57173947), Modern Geodetic Space Techniques for Global Change Monitoring

\section{REFERENCE}

Brown M T, Vivas M B, 2005. LANDSCAPE DEVELOPMENT INTENSITY INDEX Environmental Monitoring \& Assessment, 101(1-3), pp.289.

Chen P. 2007, Ecological health assessment of landscape based on landscape and remote sensing and GIS: A case study of Haiwan New Area, .Acta Scientiae Circumstance, 27 (10), pp. 1744-1752.

Dang G. F, Ji S. G. 2017. Evaluation of ecological sensitivity of land in Qinling-Bashan mountains based on GIS - A Case Study of Longnan Mountain Area Chinese Agricultural Science Bulletin, 33 (7), pp.118-127.

He C.Y, Chen J. Chen Y.H, et al, 2001.Study on mixed dynamic monitoring of land use / cover change. Chinese Journal of Natural Resources, 16 (3), pp.254-262.

LI Y.M, Guan C.W, Zhu J, 2017. Ecological Sensitivity Assessment of the Xingyun Lake Basin Based on GIS, Reservoir and Soil Conservation Research, 24 (5), pp.266-271.

Lin Y, Ji H,W, NICO Sneeuw, et al, 2017.Optimization of image classification based on fish swarm algorithm for extreme learning machine .Acta Automatic Mechanica Sinica, 48 (10).

Ma L.P, 2000. Analytic hierarchy of methods - modern statistical analysis methods and the use of (seven). Data, (7), pp. 38-39

She J.Y, Zhou D.H, Liu Z.C, et al. 2012. Analysis of Ecological Sensitivity in Wanquan River Basin Based on GIS, Chinese Agricultural Science Bulletin, 28 (10), pp. 69-73

Thanapakpawin P, Richey J, Thomas D, et al, 2007.Effects of land use change on the hydrologic regime of the Mae Chaem river basin, NW Thailand. Journal of Hydrology, 334(1-2), pp. $215-230$

White P S, Pickett S T A, 1985. Chapter1-Natural Disturbance and Patch Dynamics: An Introduction. Ecology of Natural Disturbance \& Patch Dynamics, pp.3-13.

Yin H.W, Xu J.G, Chen C.Y, et al, 2006.Analysis of ecological sensitivity in eastern Wujiang River based on GIS. GEOGRAPHY, 26 (1), pp.64-69.

Zhang S.Y, Feng C.C, Liu X.P, et al, 2015. Evaluation of construction land suitability based on ecological sensitivity analysis, Journal of Peking University Natural Science, 51 (4), pp.631-638.

Zhong L.S, Tang C.C, G.H, 2010. Zoning of tourist functions in the scenic area of Jinyintan grassland based on ecological sensitivity analysis, Chinese Journal of Applied Ecology, 21 (7), pp.1813-1819. 